\title{
Synthesis, magnetic behaviour, and X-ray structures of dinuclear copper complexes with multiple bridges. Efficient and selective catalysts for polymerization of 2,6-dimethylphenol $\uparrow$ :
}

\author{
Ramaswamy Murugavel, ${ }^{* a}$ Ramasamy Pothiraja, ${ }^{a}$ Nayanmoni Gogoi, ${ }^{a}$ Rodolphe Clérac, ${ }^{b}$ Lollita Lecren, \\ Ray J. Butcher ${ }^{c}$ and Munirathinam Nethaji ${ }^{d}$
}

The use of a potentially tridentate mono-anionic bridging ligand, 1,3-bis(3,5-dimethylpyrazol-1-yl)propan-2-ol (bdmpp-H), in assembling new dimeric copper complexes with interesting magnetic properties has been investigated. The reaction of copper hydroxide or copper acetate with phenyl phosphinic acid or diphenyl phosphinic acid in the presence of bdmpp-H produces the dinuclear complexes $[\mathrm{Cu}(\mathrm{bdmpp})(\mathrm{ppi})]_{2}(\mathbf{1})$ and $[\mathrm{Cu}(\mathrm{bdmpp})(\mathrm{dppi}-\mathrm{H})]_{2}(\mathrm{dppi})_{2}(\mathbf{2})(\mathrm{ppi}-\mathrm{H}=$ phenylphosphinic acid; dppi-H = diphenylphosphinic acid), respectively. The products have been characterized with the help of analytical, thermal, and spectroscopic (IR, UV-vis, and EPR) techniques. Single crystal X-ray diffraction studies of $\mathbf{1}$ and $\mathbf{2}$ reveal that the two bdmpp ligands hold together the dimeric copper unit in each complex through $\mu-\mathrm{O}$ alkoxide and the pyrazolyl nitrogen ligating centers. Two phenyl phosphinate ligands additionally bridge the dicopper core in $\mathbf{1}$ to result in octahedral coordination geometry around each metal ion. The diphenyl phosphinic acid acts as a terminal ligand in $\mathbf{2}$, and thus completes a square pyramidal geometry around each copper ion. Both complexes show a very short $\mathrm{Cu}$... Cu separation (3.001 and $3.065 \AA$ for $\mathbf{1}$ and 2, respectively). The investigation of the magnetic properties reveals the efficiency of the double alkoxide bridge between the two paramagnetic copper ions to mediate strong antiferromagnetic interactions $\left[J / k_{\mathrm{B}}=-620(5) \mathrm{K}\left(-431(4) \mathrm{cm}^{-1}\right)\right.$ and $-685(5)$ $\mathrm{K}\left(-476(4) \mathrm{cm}^{-1}\right)$ for $\mathbf{1}$ and 2, respectively]. Compounds $\mathbf{1}$ and 2, along with a few other copper phosphate complexes, were tested as catalysts for the oxidative polymerization of 2,6-dimethylphenol; 1 and $\mathbf{2}$ were found to be efficient catalysts with an increased selectivity for the formation of the polyphenylene ether. However a related mononuclear octahedral copper complex $\left[\mathrm{Cu}(\mathrm{imz})_{4}(\mathrm{dtbp})_{2}\right]$ (dtbp-H = di-tert-butylphosphate) was found to be more efficient.

\section{Introduction}

Assembling dimeric, tetrameric, and other oligomeric copper complexes with the aid of suitably designed polydentate ligands with multiple functional groups has been of great interest in recent times for a variety of reasons. ${ }^{1}$ In particular, there have been several studies reporting synthesis of dinuclear copper complexes, with short non-bonded contacts between the metal centers, as structural models for DNA cleavage reactions through phosphate ester hydrolysis. ${ }^{2}$ Dinuclear copper compounds have also been implicated as active catalysts for the polymerization of substituted phenols to yield poly(phenylene ether) (PPE). ${ }^{3}$ While both these aspects have already been investigated with a variety of ligands

"Department of Chemistry, Indian Institute of Technology-Bombay, Powai, Mumbai, 400076, India. E-mail: rmv@iitb.ac.in; Fax: +91-25723480

${ }^{b}$ Université Bordeaux 1; CNRS, Centre de Recherche Paul Pascal-UPR8641, 115 av. du Dr. Albert Schweitzer, 33600, Pessac, France

'Department of Chemistry, Howard University, Washington DC, 20059, USA 'Department of Inorganic and Physical Chemistry, Indian Institute of Science, Bangalore, 560012, India around a dicopper core, bridged by either $\mu$-oxo or $\mu$-hydroxo ligands, the use of multidentate ligands containing alkoxy or phenoxy groups in multi-metal compounds has continued to attract considerable attention among synthetic inorganic chemists in recent years.

We have been interested for a while in the synthesis of a variety of copper and other transition metal phosphate complexes, ${ }^{4}$ containing structurally diverse auxiliary ligands, which are useful as open framework solids or models to framework solids, ${ }^{4 a}$ complexes having interesting magnetic properties, ${ }^{4 b}$ and model compounds for phosphate diester hydrolysis. ${ }^{4 c}$ In the present study we have used a pyrazole based tridentate $\mathrm{N}_{2} \mathrm{O}^{-}$ligand, bdmpp, and synthesized two new $\mu$-alkoxo bridged dicopper complexes with interesting structural, magnetic, and catalytic properties. The results of this investigation are reported in this paper.

\section{Results and discussion}

Synthesis

Methylene bridged $\left(-\left(\mathrm{CH}_{2}\right)_{n}-\right)$ bis-pyrazolyl and bis-imidazolyl compounds have been used as convenient bridging or chelating ligands in the coordination chemistry of first row transition metal ions. ${ }^{5}$ While a variety of complexes have been synthesized with 
this type of ligand, it is often difficult to predict the type of structure (e.g. chelate or bridging mode of coordination) a priori due to the free rotation of the $\mathrm{C}-\mathrm{C}$ or $\mathrm{C}-\mathrm{N}$ bonds in the ligand backbone. In order to evaluate any such conformational changes in the presence of additional chelating ligands, we have investigated the reactions of $\mathrm{Cu}$ (II) salts with bdmpp-H in the presence of phosphinic acids. Thus, the reaction between equimolar amounts of copper hydroxide, phenylphosphinic acid, $\mathrm{Ph}(\mathrm{H}) \mathrm{PO}_{2} \mathrm{H}$ and bdmpp-H results in the formation of $[\mathrm{Cu}(\mathrm{bdmpp})(\mathrm{ppi})]_{2}$ (1) in good yield (Scheme 1). [Cu(bdmpp) (dppi-H) $]_{2}(\mathrm{dppi})_{2}(\mathbf{2})$ has been synthesized by a similar reaction from copper acetate and dppi-H in the presence of bdmpp-H (Scheme 1).

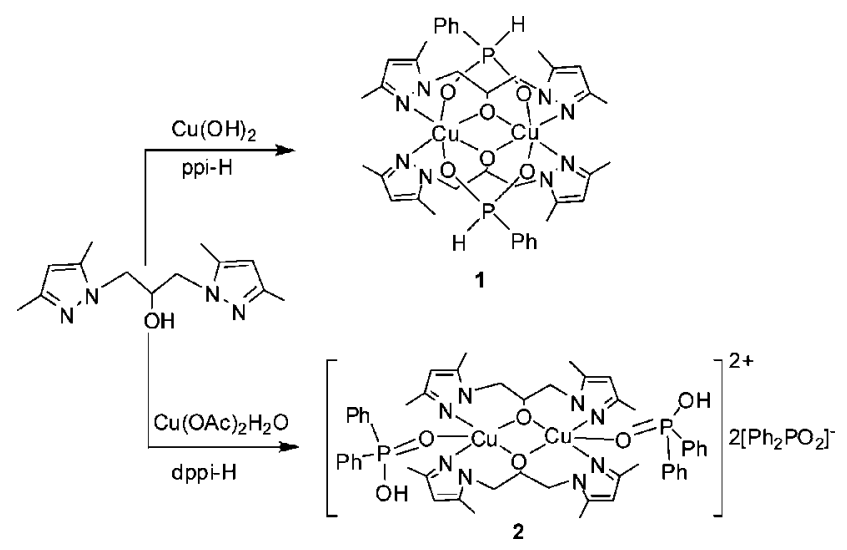

Scheme 1 Syntheses of $\mathbf{1}$ and $\mathbf{2}$.

\section{Characterization}

Complexes $\mathbf{1}$ and $\mathbf{2}$ have been characterized with the aid of elemental analysis, IR and UV-visible spectroscopic studies (Table 1). Both the compounds yielded correct elemental analysis. Strong IR bands observed at 1157, 1132, and $1018 \mathrm{~cm}^{-1}$ for $\mathbf{1}$ and 1197,1127 and $1044 \mathrm{~cm}^{-1}$ for 2 indicate the presence of $\mathrm{POO}^{-}$stretching and $\mathrm{M}-\mathrm{O}-\mathrm{P}$ vibrations. The characteristic $\mathrm{P}-$ $\mathrm{H}$ stretching vibration of the phenyl phosphinate in $\mathbf{1}$ appears as a strong band at $2284 \mathrm{~cm}^{-1}$. The UV-visible spectra of both $\mathbf{1}$ and 2 show a strong absorption in the ultraviolet region $\left(\sim 345 \mathrm{~cm}^{-1}\right)$ and a weak absorption in the visible region $\left(\sim 630 \mathrm{~cm}^{-1}\right)$. While the $345 \mathrm{~cm}^{-1}$ absorption is readily assignable to the $\pi-\pi^{*}$ or $\mathrm{n}-\pi^{*}$ transition arising out of the pyrazole groups in bdmpp, the weak absorption in the visible region is attributable to the symmetry forbidden $\mathrm{d}-\mathrm{d}$ transition of the $\mathrm{Cu}(\mathrm{II})$ ion.
Molecular structure of $\mathbf{1} \cdot \mathrm{CH}_{2} \mathrm{Cl}_{2} \cdot \mathbf{2} \mathrm{H}_{2} \mathrm{O}$. Compound $\mathbf{1}$ was crystallized from a $\mathrm{CH}_{2} \mathrm{Cl}_{2} /$ toluene mixture $(1: 1)$ at $5{ }^{\circ} \mathrm{C}$. Blue single crystals of $1 \cdot \mathrm{CH}_{2} \mathrm{Cl}_{2} \cdot 2 \mathrm{H}_{2} \mathrm{O}$ were obtained after one week by slow evaporation of the solvent in air. The copper phosphinate 1 crystallizes in the monoclinic $C 2 / \mathrm{m}$ space group with one molecule of $\mathrm{CH}_{2} \mathrm{Cl}_{2}$ and two molecules of water. The molecule has a crystallographically imposed $2 / m$ symmetry. In the dimeric structure of $\mathbf{1}$, each copper ion is firmly coordinated by two nitrogen atoms and two oxygen atoms of two bdmpp in a distorted square-planar environment (Fig. 1). The two phenylphosphinate anions symmetrically bridge the two copper ions on either side of the square plane formed by the donor atoms of the bdmpp ligands to result in a tetragonally elongated octahedral geometry for the copper ions.

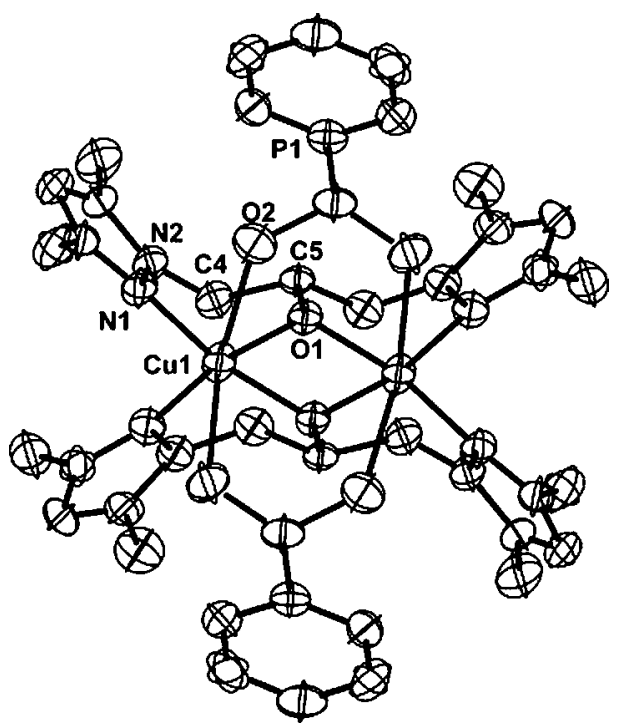

Fig. 1 ORTEP of $[\mathrm{Cu}(\mathrm{ppi})(\mathrm{bdmpp})]_{2}$ (1) (hydrogen atoms removed for clarity).

The central $\mathrm{Cu}_{2} \mathrm{O}_{2}$ ring is planar and there are two types of $\mathrm{Cu}-$ O distances in the molecule. The $\mathrm{Cu}(1)-\mathrm{O}(1)$ distance (1.931(2) $\AA$ ) is considerably shorter than the $\mathrm{Cu}(1)-\mathrm{O}(2)$ bond (2.767(4) $\AA$ ) due to the Jahn-Teller distortion. $\mathrm{The} \mathrm{Cu}(1)-\mathrm{O}(1)$ distance within the four-membered ring is slightly longer compared to similar $\mathrm{Cu}-\mathrm{O}$ distances found in $\left[\mathrm{Cu}_{2}(\mathrm{bdpo})_{2}\right]\left(\mathrm{ClO}_{4}\right)_{2} \cdot 2 \mathrm{MeOH}($ bdpo $=1,3-$ bis(2-benzimidazolyl)-propan-2-oxide) (1.930(2) and 1.923(2) $\AA$ ). ${ }^{6}$ Likewise the $\mathrm{Cu}(1)-\mathrm{O}(2)$ distance $(2.767(4) \AA)$ is one of the longest $\mathrm{Cu}-\mathrm{O}$ distances known in the literature, ${ }^{4 d}$ which can be ascribed to the combined effect of steric crowding around the copper ions and the Jahn-Teller elongation along the $z$-axis of the $\mathrm{d}^{9}-\mathrm{Cu}(\mathrm{II})$ ion.

Table 1 Comparison of selected structural parameters of dicopper complexes with a $\mathrm{Cu}_{2} \mathrm{O}_{2}$ core

\begin{tabular}{|c|c|c|c|c|c|c|}
\hline Compounds & $\mathrm{Cu} \cdots \mathrm{Cu} / \AA$ & $\mathrm{Cu}-\mathrm{O}-\mathrm{Cu} /{ }^{\circ}$ & $g$ & $J / \mathrm{K}$ & $J / \mathrm{cm}^{-1}$ & Reference \\
\hline$[\mathrm{Cu}(\mathrm{bdmpp})(\mathrm{ppi})]_{2}(\mathbf{1})$ & 3.001 & $101.95(1)$ & 2.08 & $-620(5)$ & $-431(4)$ & This work \\
\hline$[\mathrm{Cu}(\mathrm{bdmpp})(\mathrm{dppi}-\mathrm{H})]_{2}(\mathrm{dppi})_{2}(2)$ & 3.065 & $103.50(1)$ & 2.08 & $-685(5)$ & $-476(4)$ & This work \\
\hline$\left[\mathrm{Cu}_{2}(\mathrm{bdmpp})_{2}\right]\left[\mathrm{Cu}(\mathrm{MeOH}) \mathrm{Cl}_{3}\right]_{2}$ & $2.990(2)$ & 103.9(2), 98.8(2) & 2.10 & -556 & -386 & 6 \\
\hline$[\mathrm{Cu}(\mathrm{nhep}) \mathrm{Cl}]_{2}$ (Hnhep is 1-(2-hydroxyethyl)-pyrazole) & 3.055 & $105.4,104.2$ & - & $<-800 \mathrm{~K}$ & $<-500$ & 8 \\
\hline$\left[\mathrm{PBu}_{4}\right]_{2}\left[\mathrm{Cu}_{2}(\mathrm{~N} \text {-(2-hydroxyphenyl)salicylamide })_{2}\right]$ & $3.035(2)$ & $102.6(5)$ & 2.15 & -322 & -224 & 9 \\
\hline $\begin{array}{l}{\left[\mathrm{NPr}_{4}\right]_{2}\left[\mathrm{Cu}_{2}(\mathrm{~N} \text {-(2-hydroxyphenyl)-3-methoxycarbonyl- }\right.} \\
\left.\text { 4,6-dimethylsalicylamide })_{2}\right]\end{array}$ & $3.033(4)$ & $103.7(3)$ & 2.24 & -272 & -189 & 9 \\
\hline
\end{tabular}


The $\mathrm{Cu} \cdots \mathrm{Cu}$ distance in $\mathbf{1}(3.001 \AA)$ is comparable to those found in other hydroxo or alkoxo bridged dinuclear complexes, ${ }^{5,7-10}$ but is considerably shorter compared to the mono-hydroxo or monoalkoxo bridged dinuclear complexes $\left[\mathrm{Cu}_{2}(\mathrm{~L} 1)\left(\mathrm{O}_{2} \mathrm{P}(\mathrm{OAr})\right)\right]\left(\mathrm{PF}_{6}\right)_{2}$ (3.773(4) $\AA),{ }^{11}\left[(\mathrm{~L} 2) \mathrm{Cu}_{2}\left(\mathrm{O}_{2} \mathrm{P}\left(\mathrm{OCH}_{2} \mathrm{Ph}\right)_{2}\right]\left(\mathrm{ClO}_{4}\right)_{2}(3.67 \AA)^{12}\right.$ and $\left[\mathrm{Cu}_{2}(\mathrm{~L} 3)\left(\left(\mathrm{O}_{2} \mathrm{P}(\mathrm{OAr})\right)\right]\left(\mathrm{ClO}_{4}\right)_{2}(3.779(1) \AA)^{13}(\mathrm{HL} 1=2,6\right.$-bis $[$ bis $(2-$ pyridylethyl)aminomethyl]phenol; $\mathrm{Ar}=4$-nitrophenyl; $\mathrm{HL} 2=2$, 6-bis[bis(2-benzimidazolylmethyl)aminomethyl]-4-methylphenol),

HL3 $=N, N, N^{\prime}, N^{\prime}$-tetrakis $\{(6$-methyl-2-pyridyl)methyl $\}$-1,3-diaminopropan-2-ol).

The bdmpp ligands chelate the copper atoms through their alkoxide oxygen and the pyrazolyl nitrogen to form two sixmembered rings. Thus the core structure is stabilized by the formation of one four-membered $\mathrm{Cu}_{2} \mathrm{O}_{2}$ and four six-membered $\mathrm{Cu}-\mathrm{O}-$ $\mathrm{C}-\mathrm{C}-\mathrm{N}-\mathrm{N}$ metallocycles (Fig. 1). The intermolecular hydrogen bonding between the lattice water molecules and phosphinate oxygen atoms $\left(\mathrm{O}-\mathrm{H} \cdots \mathrm{O} 168^{\circ}\right)$ leads to the formation of a chainlike structure as shown in Fig. 2.

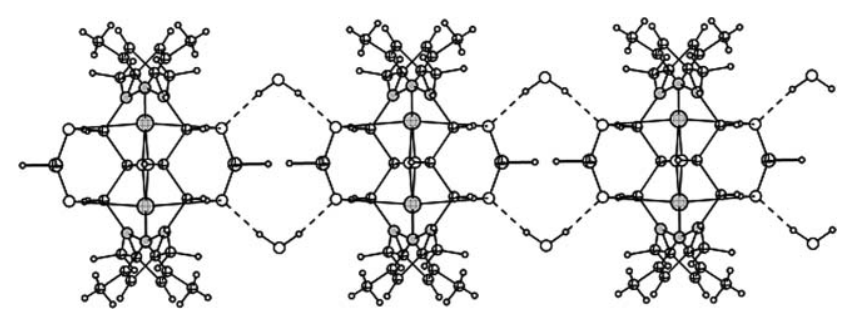

Fig. 2 Hydrogen bonding aided polymeric chain formation in $\left[\mathrm{Cu}(\text { ppi)(bdmpp) }]_{2} \mathrm{CH}_{2} \mathrm{Cl}_{2} \cdot 2 \mathrm{H}_{2} \mathrm{O}(\mathbf{1})\right.$.

Molecular structure 2. Compound 2 was crystallized from methanol at room temperature. Blue single crystals were obtained after one week by slow evaporation of the solvent. The compound crystallizes in the triclinic $P \overline{1}$ space group with a crystallographically imposed inversion centre. Each copper ion in $\mathbf{2}$ is coordinated by two nitrogen atoms and two oxygen atoms of two bdmpp ligands in a distorted square-planar environment. A phosphoryl oxygen atom at the axial position completes the square pyramidal geometry around each of the copper ions in the molecule. As in the case of $\mathbf{1}$, the two copper atoms and two alkoxy oxygen atoms, which form the central $\mathrm{Cu}_{2} \mathrm{O}_{2}$ unit, are lying in the same plane. There are two types of $\mathrm{Cu}(1)-\mathrm{O}(1)$ distances in the structure of $2(\mathrm{Cu}-\mathrm{O}(1) \# 1$ 1.938(2) $\AA$ and $\mathrm{Cu}-\mathrm{O}(1)$ 1.966(2) $\AA$ ), which are longer than those observed for $\mathbf{1}$. The larger difference in the internal angles $\left(\mathrm{Cu}-\mathrm{O}-\mathrm{Cu} 103.50(1)\right.$ and $\left.\mathrm{O}-\mathrm{Cu}-\mathrm{O} 76.49(7)^{\circ}\right)$ and the distances account for the deviation of the central ring from a regular square shape. The $\mathrm{Cu}-\mathrm{O}-\mathrm{Cu}$ angle in $2\left(103.50(1)^{\circ}\right)$ is one of the largest observed for this type of compound. ${ }^{6-10}$ Although the $\mathrm{Cu} \cdots \mathrm{Cu}$ distance in $2(3.065 \AA)$ is comparable to other dinuclear complexes with a $\mathrm{Cu}_{2} \mathrm{O}_{2}$ core, (including $\mathbf{1}$ ), it definitely lies on the upper side of the range observed for compounds with a $\mathrm{Cu}_{2} \mathrm{O}_{2}$ core.

Each bdmpp ligand in $\mathbf{2}$ chelates the two copper atoms through its alkoxide oxygen and the pyrazolyl nitrogen to form two sixmembered rings as in $\mathbf{1}$. Thus the core structure is again stabilized by the formation of one four-membered $\mathrm{Cu}_{2} \mathrm{O}_{2}$ and four sixmembered $\mathrm{Cu}-\mathrm{O}-\mathrm{C}-\mathrm{C}-\mathrm{N}-\mathrm{N}$ metallocycles (Fig. 3). The major difference between the structures of $\mathbf{1}$ and $\mathbf{2}$ is the mode in which

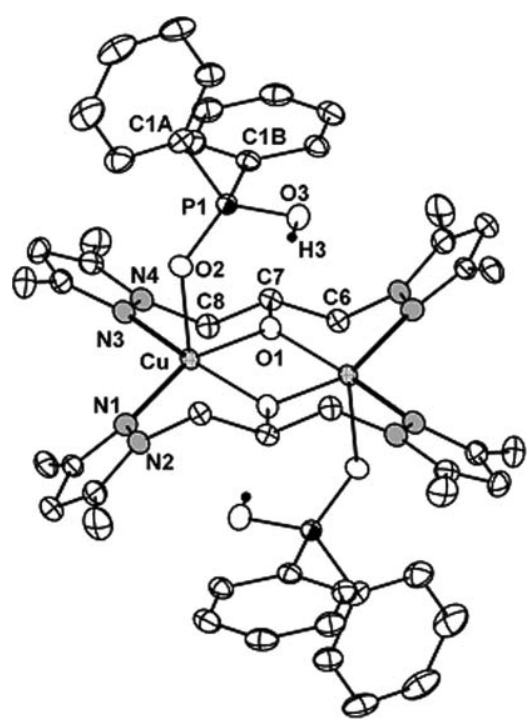

Fig. 3 ORTEP of the cationic part of $[\mathrm{Cu}(\mathrm{dppi}-\mathrm{H})(\mathrm{bdmpp})]_{2}(\mathrm{dppi})_{2}(\mathbf{2})$ (C-H hydrogen atoms removed for clarity).

the phosphinic acid ligand is coordinated to the metal. While the phenyl phosphinate in $\mathbf{1}$ bridges the two copper ions in a symmetric fashion, the diphenyl phosphinic acid in $\mathbf{2}$ prefers to coordinate to the metal in unidentate fashion, that too through its phosphoryl oxygen $(\mathrm{P}=\mathrm{O})(\mathrm{Cu}(1)-\mathrm{O}(2) 2.292(2) \AA)$ on only one side of the square plane formed by the alkoxide oxygen and pyrazolyl nitrogen atoms. This leads to a square pyramidal geometry around the metal, and leaves the complex with a di-positive $(+2)$ charge. For the charge neutrality, one uncoordinated dppi anion is additionally present for each copper atom as shown in Fig. 3. It is also of interest to note that the elongation of the axial site in $\mathbf{2}$ is considerably small, compared to 1.

Apart from the fact that the hydrogen atom on $\mathrm{O}(3)$ was located from the difference map and refined, the observed difference in the $\mathrm{P}-\mathrm{O}$ distances involving $\mathrm{O}(2)$ and $\mathrm{O}(3)^{14}(\mathrm{P}(1)-\mathrm{O}(2)$ 1.498(2) and $\mathrm{P}(1)-\mathrm{O}(3) 1.562(2) \AA)$, supports the inference that the metal is bound to the $\mathrm{P}=\mathrm{O}$ group rather than the $\mathrm{P}_{-} \mathrm{O}^{-}$terminal in 2 (Fig. 3). Additional support for this result comes from the observation that the two $\mathrm{P}-\mathrm{O}$ distances in the uncoordinated phosphinate are indeed similar $(\mathrm{P}(2)-\mathrm{O}(4) 1.510(2) \AA$ and $\mathrm{P}(2)-$ $\mathrm{O}(5) 1.527(2) \AA$ ). The phosphinate anions, apart from providing the charge stabilization, also bridge the dimeric cations through $\mathrm{O}-\mathrm{H} \cdots \mathrm{O}$ hydrogen bonding on one side $\left(\mathrm{O}-\mathrm{H} \cdots \mathrm{O} 173.7^{\circ}\right)$ and $\mathrm{C}-\mathrm{H} \cdots \mathrm{O}$ hydrogen bonding on the other side $\left(\mathrm{C}-\mathrm{H} \cdots \mathrm{O} 165.9^{\circ}\right)$ as shown in Fig. 4, to form an extended structure. The implications of the observed structural similarities and differences between the structure of $\mathbf{1}$ and $\mathbf{2}$ on the observed magnetic behaviour of these complexes are described below.

Magnetic properties of $\mathbf{1}$ and 2. The temperature dependence of the susceptibility $\chi$ (where $\chi$ is $M / H$ ) for $\mathbf{1}$ and $\mathbf{2}$ are shown in Fig. 5. The magnetic behaviors of both compounds are very similar in spite of the observed structural differences. At room temperature, these compounds possess a very weak paramagnetic susceptibility that highlights the presence of strong antiferromagnetic interaction between copper centers. On lowering the temperature, the susceptibilities slowly decrease until $150 \mathrm{~K}$ where they reach a minimum. Below $150 \mathrm{~K}$, the susceptibilities increase 


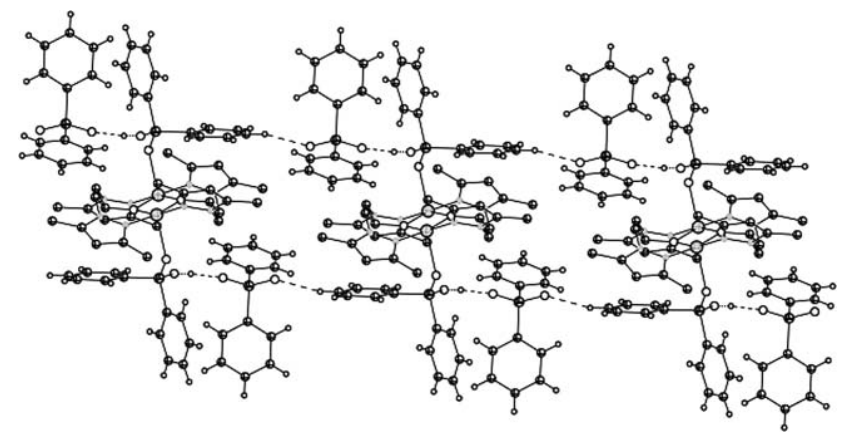

Fig. 4 Hydrogen bonding pattern in $[\mathrm{Cu}(\mathrm{dppi}-\mathrm{H})(\mathrm{bdmpp})]_{2}(\mathrm{dppi})_{2}(\mathbf{2})$.

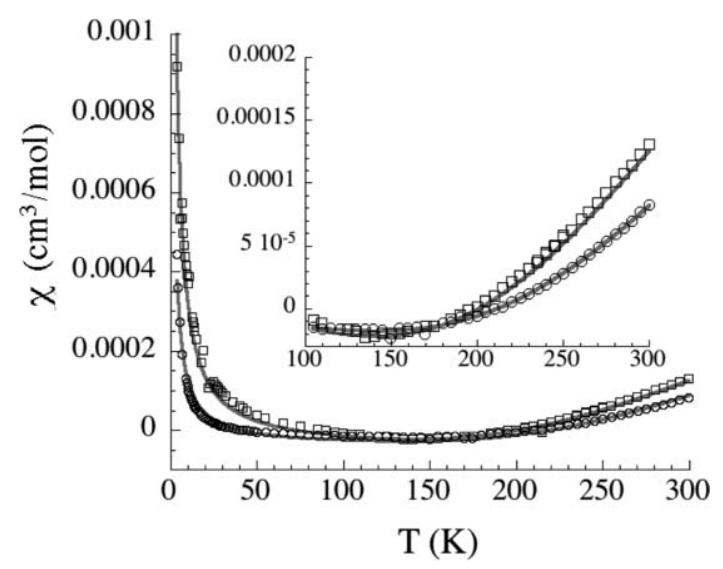

Fig. 5 Temperature dependence of the magnetic susceptibility for $\mathbf{1}(\square)$ and $2(O)$ at $1000 \mathrm{G}$. The solid lines show the best fits obtained. Inset: Zoom $\chi$ vs $T$ data in the $100-300 \mathrm{~K}$ range for $\mathbf{1}(\square)$ and $\mathbf{2}(\bigcirc)$ at $1000 \mathrm{G}$.

obeying the Curie law. On the basis of the structures described above, the magnetic properties of these complexes should be described as a dimer of $S=1 / 2$. The theoretical expression for the magnetic susceptibility of an antiferromagnetic coupled $S=$ $1 / 2$ dimer is given by the Bleaney-Bowers equation (eqn (1)). ${ }^{15}$

$$
\chi_{\text {dimer }}=\frac{2 N g^{2} \mu_{\mathrm{B}}^{2}}{k_{\mathrm{B}} T\left(3+\exp \left(-2 J / k_{\mathrm{B}} T\right)\right)}
$$

where $N$ is the Avogadro number, $\mu_{\mathrm{B}}$ is the magnetic moment and $k_{\mathrm{B}}$ is the Boltzmann constant, $g$ is the Lande factor of the given $\mathrm{Cu}_{2}$ complex, and $J$ is the magnetic exchange constant between paramagnetic ions $(S=1 / 2)$ in the dimer $\left(\boldsymbol{H}=-2 J \boldsymbol{S}_{1} \cdot \boldsymbol{S}_{2}\right)$. A second superposed magnetic contribution is observed (Fig. 5); the increase in the susceptibility value in the lowest temperature region is often seen in these dimer systems (that present a singlet ground state). This Curie type behavior (second part of eqn (2)) is associated with the presence of small amounts of paramagnetic impurities. Therefore the experimental susceptibility has been fitted to the following expression:

$$
\chi=(1-\rho) \chi_{\text {dimer }}+\rho \frac{g_{\text {imp }} N \mu_{\mathrm{B}}^{2} S_{\text {imp }}\left(S_{\text {imp }}+1\right)}{3 k_{\mathrm{B}} T}+\chi_{\text {dia }}
$$

where $\chi_{\text {dia }}$ is a fixed diamagnetic contribution calculated from the Pascal's constant, ${ }^{16} \rho$ is the fraction of paramagnetic impurity (with $g_{\text {imp }}=2$ and $S_{\text {imp }}=1 / 2$ ). The experimental data fit very well to eqn (2) (Fig. 5, solid line) and the best set of parameters obtained is $J / k_{\mathrm{B}}=-620(5) \mathrm{K}\left(431(4) \mathrm{cm}^{-1}\right)$ and $-685(5) \mathrm{K}$ (476(4) $\left.\mathrm{cm}^{-1}\right), g=2.08(1)$ and 2.08(1), $\rho=0.010$ and 0.015 , for 1 and $\mathbf{2}$, respectively. These results show that these complexes possess a diamagnetic ground state, i.e. $S=0$. Hence the enhancement of the susceptibility above $150 \mathrm{~K}$ is due to the thermal population of the triplet excited spin state $(S=1)$. Within this type of $\mathrm{Cu}$ (II) dimer unit, the magnetic interaction is governed by the overlap between the $d_{x^{2}-y^{2}}$ orbital of the copper ions and the p orbitals of the oxygen linkers. Therefore the magnitude of the $\mathrm{Cu} \cdots \mathrm{Cu}$ interaction depends strongly on the $\mathrm{Cu}-\mathrm{O}-\mathrm{Cu}$ angles and the coplanarity of $\mathrm{Cu}-\mathrm{O}_{2}-\mathrm{Cu}$ bridge ${ }^{17}$ Therefore the contribution of the $\mathrm{O}-\mathrm{P}-\mathrm{O}$ bridges to $J$ in $\mathbf{1}$ is difficult to evaluate due to the difference on the $\mathrm{Cu}-\mathrm{O}-\mathrm{Cu}$ angles between $\mathbf{1}$ and $\mathbf{2}$. Nevertheless, it is important to note that the obtained values of the magnetic interactions are close to those reported for related compounds (Table 1).

Polymerization of 2,6-dimethylphenol using 1 and 2 as catalysts. The $\mathrm{Cu}$ (II) catalyzed polymerization of 2,6-dimethylphenol (DMP) leading to the formation of poly(phenylene ether) (PPE), an industrial high performance thermoplastic, and small amount of a dimeric product, 4-(3,5-dimethyl-4-oxo-2,5-cyclohexadienylidene)-2,6-dimethyl-2,5-cyclohexadienone (DPQ), has been known for over four decades. ${ }^{18}$ Historically, a varying combination of copper salts and amines viz. tertiary alkylamines, pyridine, or imidazole derivatives have been employed for the industrial scale production of PPE. ${ }^{19}$ Recent mechanistic proposals suggest a dinuclear copper-phenoxo species as the key intermediate in the polymerization reaction ${ }^{20}$ and therefore it is expected that dinuclear copper complexes like $\mathbf{1}$ and $\mathbf{2}$ can be better catalysts and give higher selectivity in PPE over the dimer DPQ.

The catalytic activity of both the new complexes $[\mathrm{Cu}(\mathrm{bdmpp})(\mathrm{ppi})]_{2} \quad$ (1) and $[\mathrm{Cu}(\mathrm{bdmpp})(\mathrm{dppi}-\mathrm{H})]_{2}(\mathrm{dppi})_{2} \quad$ (2) in the oxidative polymerization reaction of 2,6-dimethylphenol, has been investigated (Scheme 2). For the sake of comparison, we also investigated the catalytic activity of two other related mononuclear copper complexes previously prepared in our laboratory. ${ }^{4 d}$ The results of polymerization studies carried out are summarized in Table 2. Both the complexes $\mathbf{1}$ and $\mathbf{2}$ are found to be excellent catalysts yielding high molecular weight PPE along with a very small amount of undesired DPQ (1\% for complex $\mathbf{1}$

Table 2 Polymerization of 2,6-dimethylphenol catalyzed by different copper complexes

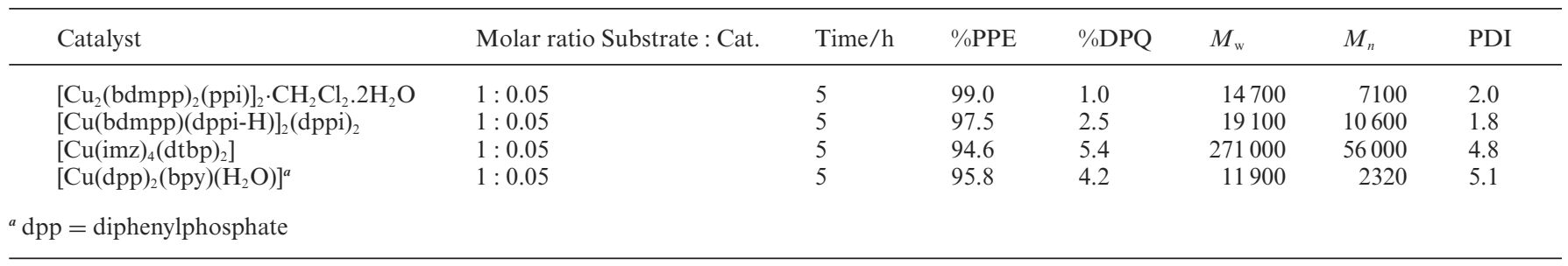




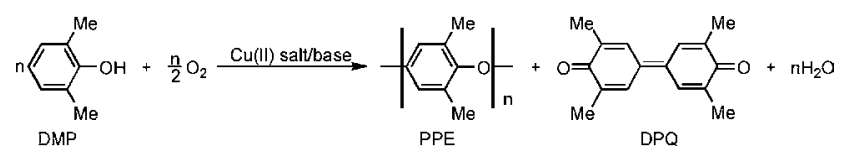

Scheme 2 Oxidative polymerization of 2,6-dimethylphenol using $\mathrm{Cu}$ (II) catalysts.

and $2.4 \%$ for complex 2 ). Thus the formation of DPQ has been suppressed significantly while other polymerization methods give DPQ in 3-5\% yield. ${ }^{21}$ The products obtained have been identified as PPE by ${ }^{1} \mathrm{H},{ }^{13} \mathrm{C}$ NMR and IR spectroscopy. The glass transition temperature $\left(T_{\mathrm{g}}\right)$ and thermal decomposition temperature $\left(T_{\mathrm{d}}\right)$ of PPE were determined to be $225^{\circ} \mathrm{C}$ and $417-481^{\circ} \mathrm{C}$, respectively ${ }^{22}$ by TG-DSC measurements. These data are in good agreement with the values reported for commercially available samples of PPE. $^{23}$

Quite surprisingly, in the case of the mononuclear complex $\mathrm{Cu}(\mathrm{dtbp})_{2}(\mathrm{imz})_{4}$, PPE of a larger molecular weight has been obtained, as compared to those obtained in the case of the dinuclear complexes $\mathbf{1}$ and $\mathbf{2}$. The observed marginal selectivity in DMP conversion, when $\mathbf{1}$ and $\mathbf{2}$ were used as catalysts, seems to indicate that a dinuclear copper species, as proposed earlier, could indeed be a key intermediate in the DMP polymerization reaction. On the contrary, the isolation of higher molecular weight polymers when $\mathrm{Cu}(\mathrm{dtbp})_{2}(\mathrm{imz})_{4}$ is used as a catalyst (Table 2 ) clearly suggests that further work involving other types of copper complexes is necessary before any generalization can be arrived at relating to the nuclearity of the copper complex and the polymerization activity. We are currently investigating this aspect.

\section{Experimental}

\section{General}

Elemental analyses were performed on a Carlo Erba Model 1106 Elemental Analyzer. Infrared spectra were recorded on a Perkin Elmer Spectrum One FT-IR spectrometer as $\mathrm{KBr}$ diluted discs. UV-vis spectra were obtained on Shimadzu UV-260 and UV160A spectrophotometers. Thermal analyses were carried out on a Perkin Elmer Pyris Diamond thermal analysis system. The molecular weight determination of the PPE polymers were carried out on a Merck La Chrom instrument with a UV detector and PL gel mixed D column calibrated with linear polystyrene standards eluting with chloroform.

All reagents, purchased from commercial sources, were used as received. 3,5-Dimethylpyrazole was prepared from hydrazine and purified by recrystallization from n-hexane. The synthesis of 1,3bis(3,5-dimethylpyrazol-1-yl)propan-2-ol was performed under an inert atmosphere of argon, but its purification was commonly performed in air. ${ }^{5}$ Sodium methoxide was prepared freshly by reacting sodium with methanol under dinitrogen atmosphere.

Synthesis of 1. $\mathrm{Cu}(\mathrm{OH})_{2}(98 \mathrm{mg}, 1 \mathrm{mmol})$ was suspended in water $(20 \mathrm{~mL})$ and bdmpp-H (248 mg, $1 \mathrm{mmol})$ in $\mathrm{MeOH}(30 \mathrm{~mL})$ was added. To the resulting solution, ppi-H (142 mg, $1 \mathrm{mmol}$ ) was added and stirred for $1 \mathrm{~h}$. The solvent was removed under vacuum and the remaining compound was dissolved in $\mathrm{CH}_{2} \mathrm{Cl}_{2}$ /toluene (3 : 1) mixture and filtered. The filtrate was kept at $5{ }^{\circ} \mathrm{C}$ for crystallization. X-Ray diffraction quality crystals were obtained after one week. Yield: $0.35 \mathrm{~g}(70 \%)$. Mp: $189-191{ }^{\circ} \mathrm{C}$. Anal. Calcd for $\mathrm{C}_{39} \mathrm{H}_{56} \mathrm{Cl}_{2} \mathrm{Cu}_{2} \mathrm{~N}_{8} \mathrm{O}_{8} \mathrm{P}_{2}\left(M_{\mathrm{r}}=1024.9\right)$ : $\mathrm{C}, 46.52 ; \mathrm{H}, 5.41 ; \mathrm{N}$, 11.13. Found: C, 46.0; H, 5.4; N, 11.3. IR $\left(\mathrm{KBr} / \mathrm{cm}^{-1}\right): 3400$ (br), 3078 (w), 2989 (m), 2929 (m), 2284 (m), 1648 (m), 1552 (s), 1469 (m), 1437 (m), 1396 (m), 1350 (w), 1303 (w), 1263 (w), 1205 (w), 1157 (vs), 1132 (vs), 1096 (m), 1032 (s), 1018 (vs), 994 (s), 912 (s), $805(\mathrm{w}), 753(\mathrm{~m}), 705(\mathrm{~m}), 646(\mathrm{~m}), 629(\mathrm{w}) . \mathrm{UV}$-vis $\left(\mathrm{CH}_{3} \mathrm{OH}\right.$, $\mathrm{nm}),\left(\varepsilon / \mathrm{cm}^{-1} \mathrm{M}^{-1}\right): 348$ (3388), 629 (64). TGA: Temp. range $/{ }^{\circ} \mathrm{C}$ (\% weight loss): 30-212 (10.2); 213-502 (48.9); 503-1188 (15.5). DSC $/{ }^{\circ} \mathrm{C}: 130$ (endo); 223 (exo); 315 (endo).

Synthesis of 2. $\mathrm{Cu}(\mathrm{OAc})_{2} \cdot \mathrm{H}_{2} \mathrm{O}(199 \mathrm{mg}, 1 \mathrm{mmol})$ was dissolved in methanol $(35 \mathrm{~mL})$ and dppi-H (436 mg, $2 \mathrm{mmol})$ was added. To the resulting turbid solution, bdmpp-H (248 $\mathrm{mg}, 1 \mathrm{mmol})$ was added, filtered and kept for crystallization to obtain X-ray diffraction quality crystals after one week. Yield: $0.67 \mathrm{~g}(90 \%)$. Mp: 196-198 ${ }^{\circ} \mathrm{C}$. Anal. Calcd for $\mathrm{C}_{74} \mathrm{H}_{80} \mathrm{Cu}_{2} \mathrm{~N}_{8} \mathrm{O}_{10} \mathrm{P}_{4}\left(M_{\mathrm{r}}=1492.5\right)$ : C, 59.55; H, 5.40; N, 7.51. Found: C, 58.1; H, 5.5; N, 7.5. IR (KBr, cm ${ }^{-1}$ ): 3397 (br), 3053 (m), 2925 (m), 1690 (m), 1548 (m), 1440 (s), 1398 (m), 1366 (s), 1197 (m), 1127 (s), 1044 (m), 940 (m), 912 (m), 697 (s). UV-vis $\left(\mathrm{CH}_{3} \mathrm{OH} / \mathrm{nm}\right),\left(\varepsilon / \mathrm{cm}^{-1} \mathrm{M}^{-1}\right): 344$ (6131), 635 (186). TGA: Temp. range $/{ }^{\circ} \mathrm{C}$ (\% weight loss): 50-193 (6.4); 194-302 (39.4); 303-525 (36.5). DSC/ ${ }^{\circ} \mathrm{C}: 138$ (endo); 203 (endo); 356 (exo).

Magnetic studies. The magnetic susceptibility measurements were obtained with the use of a Quantum Design SQUID magnetometer MPMS-XL operating between 1.8 and $300 \mathrm{~K}$. Measurements were performed on finely ground crystalline samples of 1 (26.57 mg) and 2 (20.30 mg). Magnetic data were corrected for the sample holder.

\section{X-Ray structure determination of 1 and 2}

The crystals for X-ray diffraction studies for compounds $\mathbf{1}$ and $\mathbf{2}$ were grown using the procedures described above. A suitable single crystal of each compound was used for cell determination and intensity data collection on a Bruker AXS CCD diffractometer (at $293 \mathrm{~K}$ for 1 and $103 \mathrm{~K}$ for 2 ). The structures of both the compounds were solved using direct methods as implemented in SHELXS-97 and the structures were refined using the full-matrix least square method on $F^{2}$ using SHELXL-97. All non-hydrogen atoms were refined with anisotropic thermal parameters. The hydrogen atoms were fixed at calculated positions and were refined subsequently using a riding model. The crystal data and selected details of the refinement are listed in Table 3. The details of final refined structures are provided as ESI

CCDC reference numbers 631558 and 631559.

For crystallographic data in CIF or other electronic format see DOI: $10.1039 / \mathrm{b} 618559 \mathrm{~b}$

\section{Polymerization of 2,6-dimethylphenol}

In a typical experiment, the substrate solution is prepared freshly by mixing a methanol $(10 \mathrm{~mL})$ solution of $\mathrm{NaOMe}(129 \mathrm{mg}$, $2.4 \mathrm{mmol})$ and a toluene $(20 \mathrm{~mL})$ solution of 2,6-dimethylphenol (244 mg, $2 \mathrm{mmol}$ ). The resulting yellow color solution is added dropwise to a methanol $(25 \mathrm{~mL})$ solution of the complex 2 $(118 \mathrm{mg}, 0.1 \mathrm{mmol})$ and stirred at $50{ }^{\circ} \mathrm{C}$, under a continuous current of air until all the phenol has reacted. The reaction mixture is slowly added to a $100 \mathrm{~mL}$ methanol solution containing 
Table 3 Crystal data for $\mathbf{1}$ and $\mathbf{2}$

\begin{tabular}{|c|c|c|}
\hline & 1 & 2 \\
\hline Empirical formula & $\mathrm{C}_{39} \mathrm{H}_{56} \mathrm{Cl}_{2} \mathrm{Cu}_{2} \mathrm{~N}_{8} \mathrm{O}_{8} \mathrm{P}_{2}$ & $\mathrm{C}_{74} \mathrm{H}_{80} \mathrm{Cu}_{2} \mathrm{~N}_{8} \mathrm{O}_{10} \mathrm{P}_{4}$ \\
\hline FW & 1095.74 & 1492.42 \\
\hline Temp/K & 293(2) & $103(2)$ \\
\hline Wavelength/§ & 0.71073 & 0.71073 \\
\hline Crystal system & Monoclinic & Triclinic \\
\hline Space group & $C 2 / m$ & $P \overline{1}$ \\
\hline$a / \AA$ & $16.360(5)$ & $13.206(2)$ \\
\hline$b / \AA$ & $17.733(5)$ & $13.439(2)$ \\
\hline$c / \AA$ & $9.758(5)$ & $13.497(2)$ \\
\hline$a /^{\circ}$ & - & $71.321(3)$ \\
\hline$\beta /^{\circ}$ & $125.619(5)$ & $61.987(2)$ \\
\hline$\gamma /{ }^{\circ}$ & - & $69.552(3)$ \\
\hline$V / \AA^{3}$ & $2301(2)$ & $1945.8(5)$ \\
\hline$Z$ & 2 & 1 \\
\hline$D($ calcd $) / \mathrm{Mg} \mathrm{m}^{-3}$ & 1.581 & 1.274 \\
\hline Abs. coeff. $/ \mathrm{mm}^{-1}$ & 1.286 & 0.688 \\
\hline$F(000)$ & 1132 & 778 \\
\hline Crystal size $/ \mathrm{mm}^{3}$ & $0.53 \times 0.29 \times 0.07$ & $0.56 \times 0.5 \times 0.12$ \\
\hline$\theta$ range $/^{\circ}$ & 1.91 to 28.04 & 1.65 to 28.41 \\
\hline Data/restraints/params & $2813 / 0 / 210$ & $9035 / 0 / 448$ \\
\hline Goodness-of-fit on $F^{2}$ & 0.825 & 1.005 \\
\hline$R_{1}[I>2 \sigma(I)]$ & 0.0446 & 0.0476 \\
\hline$R_{2}[I>2 \sigma(I)]$ & 0.1257 & 0.1249 \\
\hline
\end{tabular}

$2 \mathrm{~mL}$ concentrated $\mathrm{HCl}$ so that the catalyst gets destroyed. The precipitated polymer is filtered out and washed several times with methanol. The re-precipitation from a chloroform solution in methanol yielded the polymer as an off-white powder. Yield = $0.21 \mathrm{~g}(86 \%) .{ }^{1} \mathrm{H}$ NMR (400 MHz, $\left.\mathrm{CDCl}_{3}\right) \delta 2.08(\mathrm{~s}, 6 \mathrm{H}), 6.46(\mathrm{~s}$, $2 \mathrm{H}) ;{ }^{13} \mathrm{C} \mathrm{NMR}\left(100 \mathrm{MHz}, \mathrm{CDCl}_{3}\right): \delta 16.92,114.62,132.71,145.62$, 154.90; IR (KBr) cm ${ }^{-1}: 3430,2922,1604,1471,1305,1188,1020$, 857.

At the end of the polymerization reaction, $1 \mathrm{~mL}$ of the reaction mixture was diluted to $10 \mathrm{~mL}$ with toluene. This solution gave a UV-visible absorption with a maximum at $421 \mathrm{~nm}$, which was used to determine the amount of DPQ formed. The molar extinction coefficient of DPQ at $421 \mathrm{~nm}$ is determined to be $54000 \mathrm{M}^{-1} \mathrm{~cm}^{-1}$. The amount of DPQ formed is reported as a percentage with respect to the initial amount of 2,6-dimethylphenol.

\section{Acknowledgements}

This work was supported by the DST, New Delhi (through a Swarnajayanti Fellowship to RM and a SERC project) and by the CNRS, the University of Bordeaux 1, the Conseil Régional d'Aquitaine. We also thank the SAIF, IIT-Bombay, for characterization data and Prof. Anil Kumar for GPC data. R. P. and N. G. thank the CSIR, New Delhi for a research fellowship.

\section{References}

1 A. L. Gavrilova and B. Bosnich, Chem. Rev., 2004, 104, 349.
2 (a) D. S. Sigman, A. Mazumder and D. M. Perrin, Chem. Rev., 2003, 93, 2295; (b) D. S. Sigman, R. W. Bruice, A. Mazumder and C. L. Sutton, Acc. Chem. Res., 1993, 26, 98.

3 (a) J. Gao, J. H. Reibenspies and A. E. Martell, Inorg. Chim. Acta, 2002, 338, 157; (b) A. M. Schuitema, P. G. Aubel, I. A. Koval, M. Engelen, W. L. Driessen, J. Reedijk, M. Lutz and A. L. Spek, Inorg. Chim. Acta, 2003, 355, 374; (c) J. Gao, S. H. Zhong and R. A. Zingaro, J. Mol. Catal. A: Chem., 2004, 207, 15; (d) W. L. Driessen, P. J. Baesjou, J. E. Bol, H. Kooijman, A. L. Spek and J. Reedijk, Inorg. Chim. Acta, 2001, 324, 16; (e) S. J. A. Guieu, A. M. M. Lanfredi, C. Massera, L. D. Pachon, P. Gamez and J. Reedijk, Catal. Today, 2004, 96, 259.

4 (a) R. Murugavel, M. G. Walawalkar, M. Dan, H. W. Roesky and C. N. R. Rao, Acc. Chem. Res., 2004, 37, 763; (b) R. Murugavel, M. Sathiyendiran, R. Pothiraja, M. G. Walawalkar, T. Mallah and E. Riviére, Inorg. Chem., 2004, 43, 945; (c) R. Murugavel, M. Sathiyendiran, R. Pothiraja and R. J. Butcher, Chem. Commun., 2003, 2546; (d) R. Murugavel and M. Sathiyendiran, Chem. Lett., 2001, 84; (e) R. Murugavel, M. Sathiyendiran and M. G. Walawalkar, Inorg. Chem., 2001, 40, 427; (f) M. Sathiyendiran and R. Murugavel, Inorg. Chem., 2002, 41, 6404; (g) R. Pothiraja, M. Sathiyendiran, R. J. Butcher and R. Murugavel, Inorg. Chem., 2004, 43, 7585; $(h)$ R. Pothiraja, M. Sathiyendiran, R. J. Butcher and R. Murugavel, Inorg. Chem., 2005, 44, 6314; (i) R. Murugavel and S. Kuppuswamy, Angew. Chem., Int. Ed., 2006, 45, 7022; (j) R. Murugavel, S. Kuppuswamy, R. Boomishankar and A. Steiner, Angew. Chem., Int. Ed., 2006, 45, 5536-5540.

5 P. Gamez, J. Harra, O. Roubeau, W. L. Driessen and J. Reedijk, Inorg. Chim. Acta, 2001, 324, 27.

6 F. Zippel, F. Ahlers, R. Werner, W. Haase, H. F. Nolting and B. Krebs, Inorg. Chem., 1996, 35, 3409.

7 M. Koikawa, H. Yamashita and T. Tokii, Inorg. Chem. Commun., 2003, 6, 157.

8 S. Tanase, E. Bouwman, W. L. Driessen, J. Reedijk and R. Gelder, Inorg. Chim. Acta, 2003, 355, 458.

9 M. Koikawa, H. Okawa, N. Matsumoto, M. Gotoh, S. Kida and T. Kohzuma, J. Chem. Soc., Dalton Trans., 1989, 2089.

10 M. Koikawa, M. Nakashima and T. Tokii, Inorg. Chim. Acta, 1998, 277, 134.

11 M. M. Tahir, K. D. Karlin, Q. Chen and J. Zubieta, Inorg. Chim. Acta, 1993, 207, 135.

12 M. Wall, R. C. Hynes and J. Chin, Angew. Chem., Int. Ed. Engl., 1993, 32, 1633.

13 K. Yamaguchi, F. Akagi, S. Fujinami, M. Suzuki, M. Shionoya and S. Suzuki, Chem. Commun., 2001, 375.

14 M. A. De Rosch and W. C. Trogler, Inorg. Chem., 1990, 29, 2409.

15 (a) R. L. Carlin, Magnetochemistry, Springer, Berlin, 1986; (b) B. Bleaney and K. D. Bowers, Proc. R. Soc. London, Ser. A, 1952, 214, 451.

16 E. A. Boudreaux and L. N. Mulay, Theory and Applications of Molecular Paramagnetism, John Wiley \& Sons, New York, 1976.

17 (a) P. J. Hay, J. C. Thibeault and R. Hoffmann, J. Am. Chem. Soc., 1975, 97, 4884; (b) O. Kahn, Molecular Magnetism, Wiley-VCH, New York, 1993.

18 A. S. Hay, H. S. Stafford, G. F. Endres and J. W. Eustance, J. Am. Chem. Soc., 1959, 81, 6336.

19 (a) A. S. Hay, J. Polym. Sci., Part A: Polym. Chem., 1998, 36, 505; (b) P. Gamez, C. Simons, G. Aromi, W. L. Driessen, G. Challa and J. Reedijk, Appl. Catal., A, 2001, 214, 187.

20 P. Gamez, C. Simons, R. Steensma, W. L. Driessen, G. Challa and J. Reedijk, Eur. Polym. J., 2001, 37, 1293.

21 F. J. Viersen, J. Renkema, G. Challa and J. Reedijk, J. Polym. Sci., Part A: Polym. Chem., 1992, 30, 901.

22 The $T_{\mathrm{g}}$ and $T_{\mathrm{d}}$ correspond to the polymer prepared using $\mathbf{2}$ as the catalyst.

23 F. E. Karasz, H. E. Blair and J. M. O'Reilly, J. Polym. Sci., Part A2, $1968,6,1141$. 